\title{
Notes on the vocalizations of Riverbank Warbler (Basileuterus rivularis)
}

Peter Boesman

In the following we briefly analyze and compare voice of the three races of Riverbank Warbler (Basileuterus rivularis). We also try to quantify the extent of any vocal differences using the criteria proposed by Tobias et al. (2010), as a support for taxonomic review. We have made use of sound recordings available on-line from Xeno Canto (XC) and Macaulay Library (ML).

A comparison of song, illustrated with sonograms: mesoleuca:

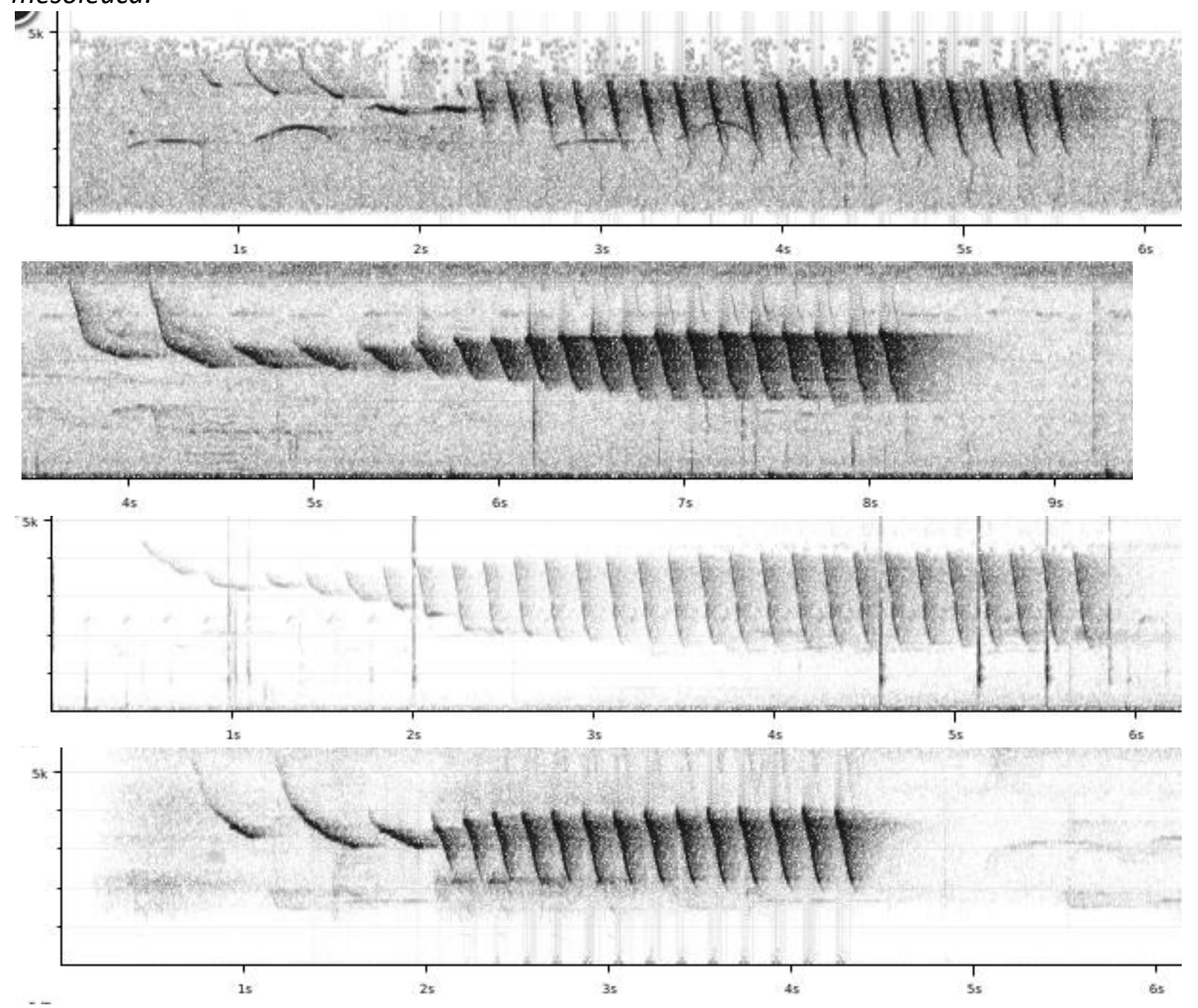




\section{HANDBOOK OF THE \\ Aluve}

\section{ORNITHOLOGICAL NOTES}
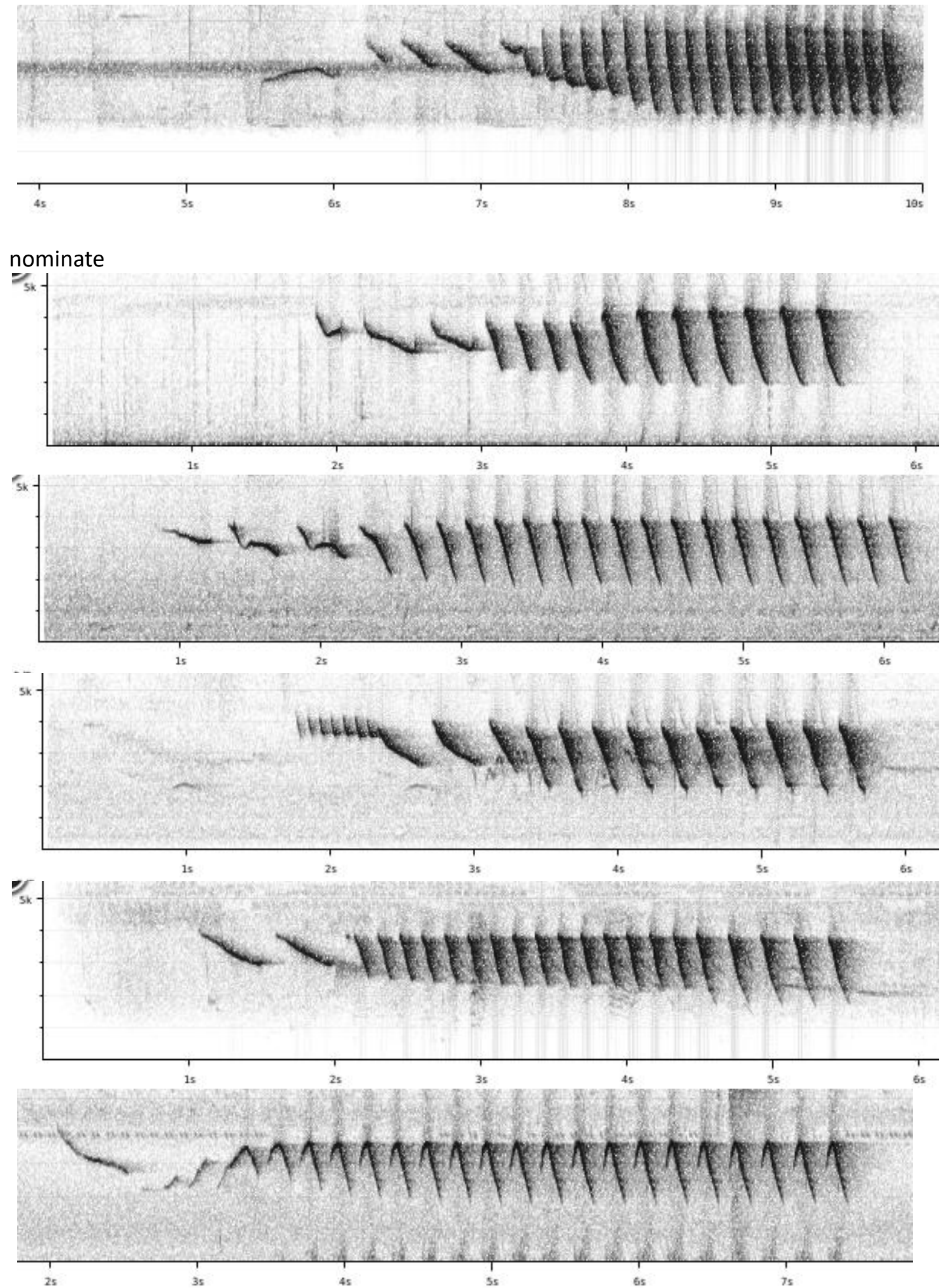

Difference in song is rather subtle, but pace especially towards the end is clearly slower in nominate (c. 5 notes in last second of song phrase vs 6-8 notes, score 2 ). 


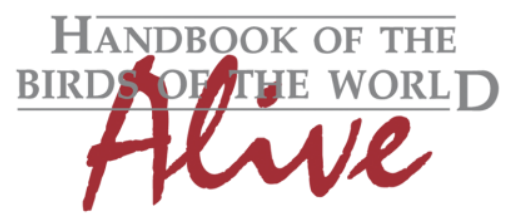

\section{ORNITHOLOGICAL NOTES}

\section{bolivianus}
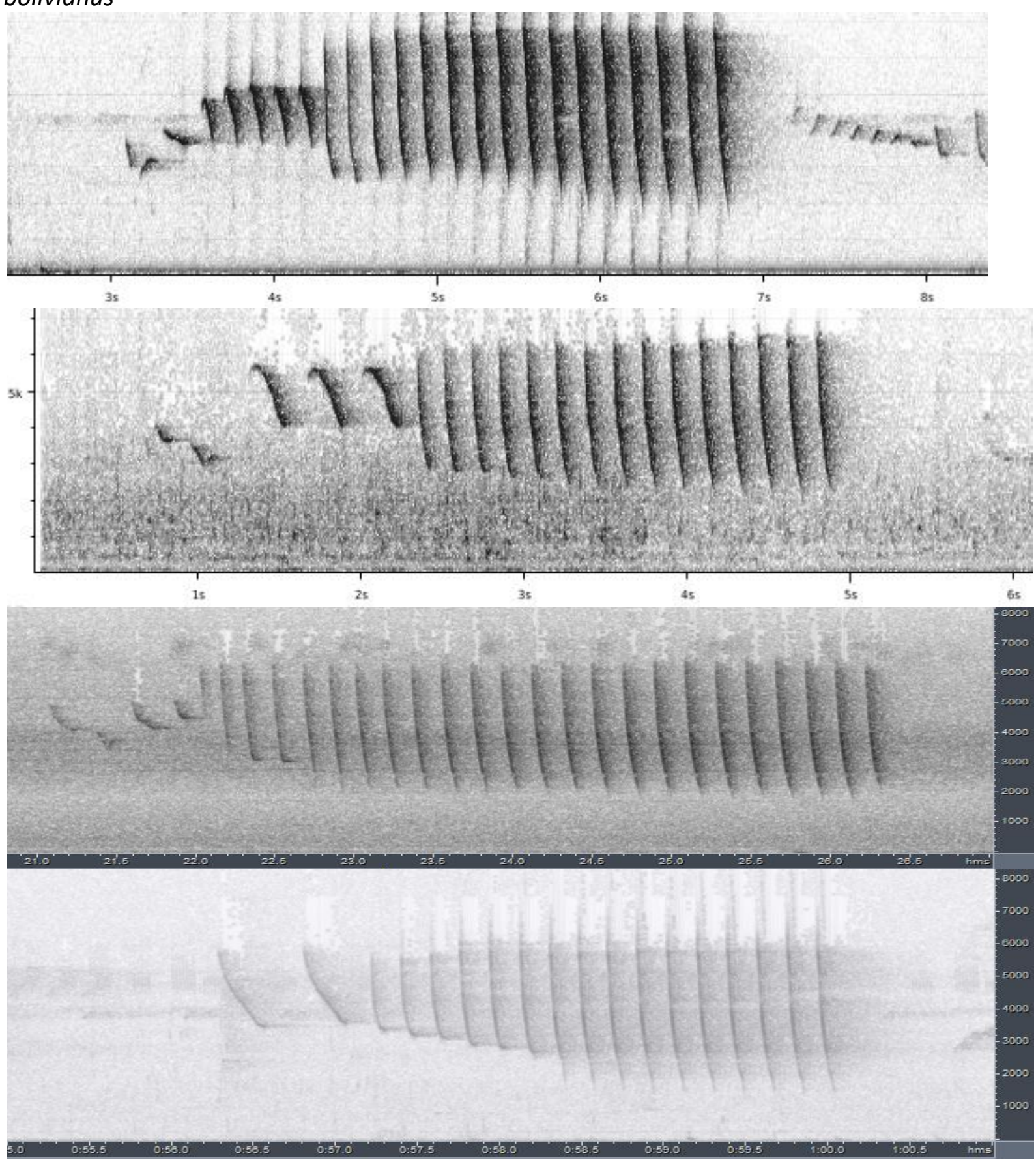

bolivianus seems to reach higher frequencies (very much like Buff-rumped Warbler $M$. fulvicauda, and there is possibly even some confusion in this region, with 2 recordings from the Bolivian foothills catalogued as Buff-rumped Warbler ).

Pace at the end matches mesoleuca, not nominate.

We can thus conclude that vocal differences are rather subtle, with nominate having a slower end pace than the two other races (score 2), and bolivianus having higher-pitched notes, as in closely-related M. fulvicauda. 
This note was finalized on 27th June 2016, using sound recordings available on-line at that moment. We would like to thank in particular the many sound recordists who placed their recordings for this species on XC and $\mathrm{ML}$.

\section{References}

Tobias, J.A., Seddon, N., Spottiswoode, C.N., Pilgrim, J.D., Fishpool, L.D.C. \& Collar, N.J. (2010). Quantitative criteria for species delimitation. Ibis 152(4): 724-746.

\section{Recommended citation}

Boesman, P. (2016). Notes on the vocalizations of Riverbank Warbler (Basileuterus rivularis). HBW Alive Ornithological Note 375. In: Handbook of the Birds of the World Alive. Lynx Edicions, Barcelona. (retrieved from http://www.hbw.com/node/1252926 on 30 November 2016). 